\title{
Intracranial extra-axial hemangioma in a newborn: A case report and literature review
}

\author{
Marcos Dalsin, Rafael Sodré Silva, Jennyfer Paula Galdino Chaves ${ }^{1}$, Francine Hehn Oliveira², \\ Ápio Cláudio Martins Antunes ${ }^{3}$, Leonardo Modesti Vedolin ${ }^{4}$
}

\footnotetext{
Department of Neurosurgery, Hospital de Clínicas de Porto Alegre, ${ }^{1}$ Universidade Federal de Rio Grande, ${ }^{2}$ Department of Pathology, Hospital de Clínicas de Porto Alegre, ${ }^{3}$ Head of Neurosurgery Unit, Hospital de Clínicas de Porto Alegre, ${ }^{4}$ Head os Radiology Unit, Hospital de Clínicas de Porto Alegre, RS, Brazil

E-mail: *Marcos Dalsin - marcosdalsin@gmail.com; Rafael Sodré Silva - sodrers@hotmail.com; Jennyfer Paula Galdino Chaves - jennyfergaldino@hotmail.com; Francine Hehn Oliveira - franhehn@gmail.com; Ápio Cláudio Martins Antunes - aantunes@hcpa.edu.br;

Leonardo Modesti Vedolin - leonardovedolin@hotmail.com

*Corresponding author
}

Received: 02 September $15 \quad$ Accepted: 06 Febaruary $16 \quad$ Published: 13 May 16

\begin{abstract}
Background: Congenital hemangiomas are benign vascular tumors, and the intracranial counterpart was described in very few cases.

Case Description: A newborn presented with an intracranial tumor associated with an arachnoid cyst, diagnosed by antenatal ultrasound at 37 weeks of gestation. Surgery was indicated due to increased head circumference and bulging fontanelle, and a complete resection of an extra-axial red-brown tumor was performed at the $3^{\text {rd }}$ week of life. Microscopy revealed a hemangioma.

Conclusion: Hemangioma is a rare differential diagnosis that must be considered in extra-axial intracranial tumors affecting infants and neonates. The radiological features are not helpful in differentiating from other tumors, and surgery is indicated when the diagnosis is uncertain or whenever there are signs of increased intracranial pressure.
\end{abstract}

Key Words: Brain tumor, intracranial hemangioma, newborn

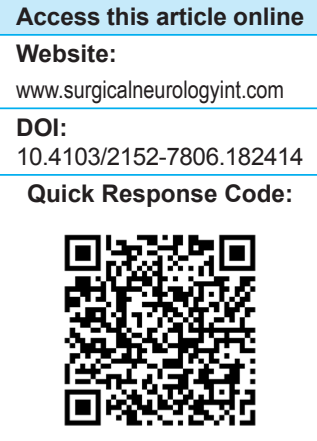

\section{INTRODUCTION}

Hemangioma is an uncommon benign vascular intracranial tumor, and the occurrence in newborns is extremely rare. ${ }^{[3,8]}$ Despite being the most common tumor in childhood, hemangiomas rarely affect the central nervous system (CNS).[2] When it occurs, the clinical presentation is usually with increased head circumference and intracranial hypertension signals. ${ }^{[2,3]}$ Although it can undergo spontaneous regression, surgical resection is the treatment of choice. ${ }^{[3]}$

\section{CASE REPORT}

A 30-year-old woman, with gestational diabetes and at second pregnancy, was admitted to the hospital at 38 weeks gestation, after diagnosis of a large ultrasound fetal brain tumor at 37 weeks gestation [Figure 1]. She had been attending regular antenatal examination, including normal fetal ultrasound at 12, 22, 28, and 32 weeks of gestation, without a family history of brain tumor.

The patient, a full-term female baby, was delivered by cesarean section, weighing $4455 \mathrm{~g}$ with an Apgar score of 5-9. On physical examination at birth, there were no skin

This is an open access article distributed under the terms of the Creative Commons Attribution-NonCommercial-ShareAlike 3.0 License, which allows others to remix tweak, and build upon the work non-commercially, as long as the author is credited and the new creations are licensed under the identical terms.

For reprints contact: reprints@medknow.com

How to cite this article: Dalsin M, Silva RS, Galdino Chaves JP, Oliveira FH, Martins Antunes ÁC, Vedolin LM. Intracranial extra-axial hemangioma in a newborn: A case report and literature review. Surg Neurol Int 2016;7:S3।4-6.

http://surgicalneurologyint.com/Intracranial-extra-axial-hemangioma-in-a-newborn:A-case-report-and-literature-review/ 


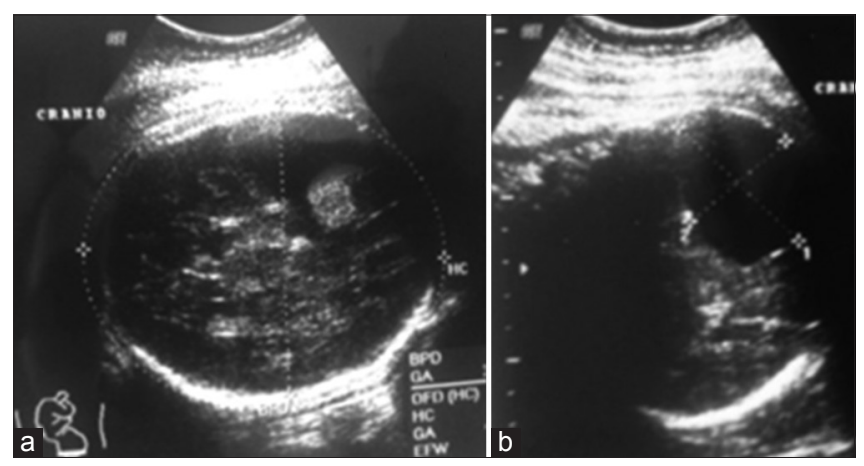

Figure I: Fetal ultrasound at $\mathbf{3 7}$ weeks gestation. (a) Axial view showing a solid echogenic mass in the left hemisphere $(18 \mathrm{~mm})$. (b) Axial view showing a large cyst $(5 \mathrm{I} \mathrm{mm} \times 38 \mathrm{~mm} \times 63 \mathrm{~mm}$ ) adjacent to the tumor

lesions, the head circumference was $37 \mathrm{~cm}$ (higher than $95^{\text {th }}$ percentile), the anterior fontanelle was normotensive, and the neurologic examination was normal.

Magnetic resonance imaging (MRI) demonstrated a solid mass lesion with intense gadolinium enhancement in the left middle fossa, associated with a large cyst dislocating the left hemisphere and the brainstem [Figure 2]. Due to progressive head enlargement and tense fontanelle, two transfontanel punctures on the $1^{\text {st }}$ and $2^{\text {nd }}$ weeks were performed.

A small temporal craniotomy was done at the $3^{\text {rd }}$ week of life: An extra-axial red-brown tumor was completely removed after coagulation of a clear vascular pedicle and the cyst was communicated with the subarachnoid cisterns. Microscopy revealed a tumor showing juvenile forms of capillary hemangioma and canalization of most vessels [Figure 3].

Postoperative MRI demonstrated complete resection of the tumor, but a residual extra-axial cyst [Figure 4]. The patient had a satisfactory recovery without neurological deficits and was discharged at the $5^{\text {th }}$ week of life with normal open fontanels, without signs of intracranial hypertension, and referred to outpatient follow-up.

\section{DISCUSSION}

\section{Epidemiology}

In childhood, malignant brain tumors are the most common solid organ tumors, accounting approximately for $20-30 \%$ of the cancers in this age. ${ }^{[7]}$ Large intracranial lesions in the $1^{\text {st }}$ year of life are uncommon ${ }^{[2]}$ and more likely to be primitive neuroectodermal tumors, desmoplastic infantile astrocytoma, teratomas, and choroid plexus papilloma. ${ }^{[2,7]}$ Congenital brain tumors occurs in an incidence of 1.1 to 3.3 per 100.000 newborns and constitute $<2 \%$ of all pediatric brain tumors. ${ }^{[8]}$

Hemangiomas are the most common tumors of infancy, ${ }^{[2,5]}$ present congenitally or in early infancy, ${ }^{[6]}$ and

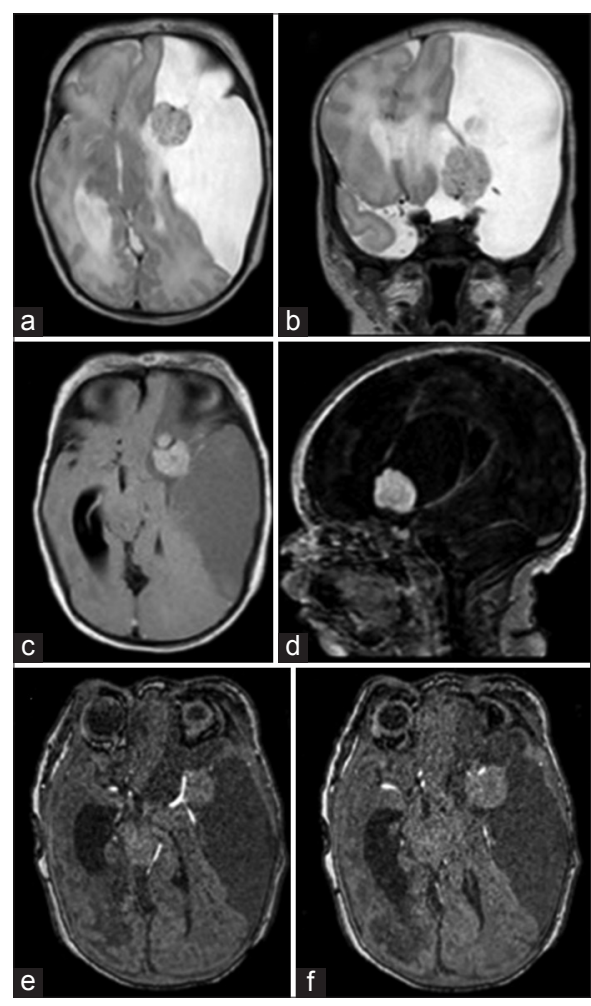

Figure 2: Preoperative magnetic resonance imaging at 5 days of life: (a) Axial T2-weighted. (b) Coronal T2-weighted sequence demonstrating a lobulated heterogeneous solid mass $(22 \mathrm{~mm} \times 18 \mathrm{~mm} \times 10 \mathrm{~mm})$ associated with a large extra-axial cyst that compress and dislocate brainstem of the left hemisphere. (c) AxialT2/fluid attenuation inversion recovery-weighted sequence demonstrating hyperintense lesion. (d) Sagittal TI-weighted with gadolinium showing intense enhancement of the lesion after contrast. (e and $f$ ) Magnetic resonance angiography showing the intense relation of the tumor with the left middle cerebral artery and one branch inside the mass

described as benign vascular tumor typically involving the skin of the face, scalp, neck, and chest. ${ }^{[2,5,6]}$ Although a common skin incidence, hemangiomas involving the CNS are extremely rare, ${ }^{[2,6,8]}$ with the prevalence of $0.37-0.57 \%$ in the overall pediatric population, even more rare in the $1^{\text {st }}$ year of life. ${ }^{[8]}$

\section{Clinical and radiological features}

The most common clinical presentation in neonates is the enlargement of head circumference (62\%) and/or signs of raised intracranial pressure such as vomiting and irritability $(14 \%),,^{[2,3,8]}$ instead of cerebral cavernous malformations whose main symptoms are due to hemorrhage. ${ }^{[4]}$ Seizures and other neurologic symptoms are less frequent. ${ }^{[8]}$ During the perinatal period, early diagnosis is important and requires an obstetric ultrasound for monitoring. ${ }^{[8]}$ After delivery, cranial ultrasound demonstrates a well-circumscribed echogenic solid mass, ${ }^{[3]}$ and computed tomography and MRI are useful to demonstrate the brain tumor, ${ }^{[8]}$ but are not helpful in differential diagnosis. ${ }^{[2]}$ In the few reported cases, the lesions were well-defined, highly vascularized 


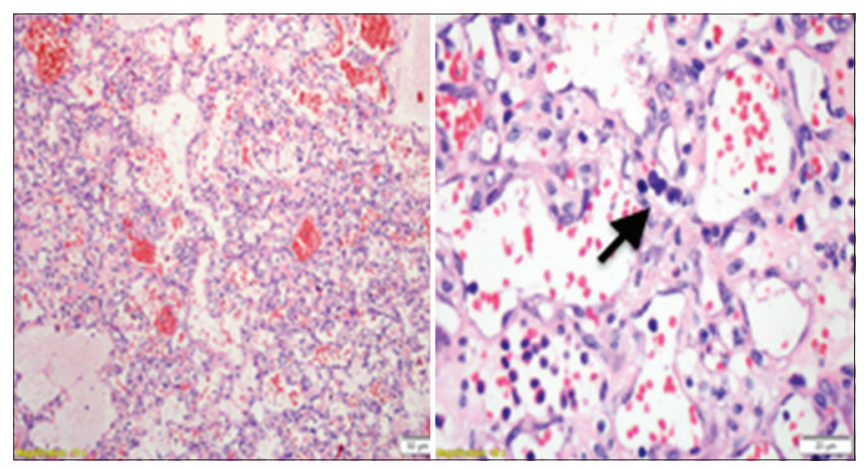

Figure 3: Low power view of tumor showing juvenile forms of capillary hemangioma and canalization of most vessels (left: $\mathrm{H}$ and $\mathrm{E}, \times 4$ ); high power view of tumor demonstrating plump endothelial that lines vascular spaces and mitotic figure (arrow) (right: $H$ and $E, \times 40$ )

extra-axial lesions, with intense contrast enhancement, calcification areas, ${ }^{[2,8]}$ and high-signal intensity on both Tl-weighted and T2-weighted images in MRI. ${ }^{[8]}$

\section{Anatomopathological considerations}

Hemangioma is a CNS vascular neoplasm that may occur sporadically or exhibit autosomal dominant inheritance. ${ }^{[4,8]}$ It is usually an extra-axial lesion, involving the dura mater, dural sinuses, ventricles, and tentorium, ${ }^{[2,3]}$ often associated with cutaneous lesions, ${ }^{[8]}$ and have the potential to grow and regress spontaneously over the time. ${ }^{[2]}$ The differential diagnosis includes hemangioblastoma, hemangioendothelioma, and hemangiopericytoma. ${ }^{[6]}$

Macroscopically, the tumor is encapsulated with high-flow vascular arterial and venous pedicles. Histologically, hemangiomas are benign vascular neoplasms characterized by thin-walled endothelial-lined dilated spaces that can be filled with blood or thrombus. ${ }^{[2,8]}$ The vascular nature can be confirmed by immunohistochemistry to CD31 and CD34. ${ }^{[3,6]}$

\section{Prognosis and treatment}

Because these lesions are extremely uncommon, the natural evolution is unclear. ${ }^{[2]}$ Surgical resection is the treatment of choice ${ }^{[3]}$ and should be indicated for large tumors and whenever signs of intracranial hypertension caused by tumor. ${ }^{[2]}$ Spontaneous regression of extracranial hemangiomas during childhood is common, ${ }^{[1]}$ so small intracranial tumors associated with cutaneous hemangiomas could be followed to watch for regression. ${ }^{[2,6]}$ Tumor biopsy is unsafe because of the high vascularity of the tumor. ${ }^{[1]}$

\section{CONCLUSION}

Although rare, hemangioma is a differential diagnosis that must be considered in extra-axial intracranial

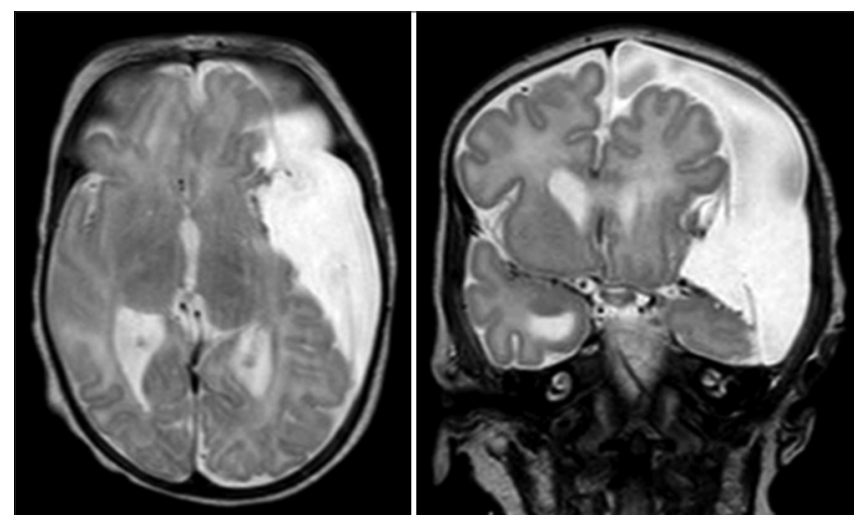

Figure 4: Postoperative magnetic resonance imaging 7 days after surgery. Axial and coronal T2-weighted demonstrating complete resection of the lesion and persistence of large extra-axial cyst, although smaller than preoperatively

tumors affecting infants. Because the radiological features are not helpful in differentiating other tumors, surgery is indicated when the diagnosis is uncertain or whenever there are signs of increasing mass effect and/or intracranial hypertension.

The termination of pregnancy in case of defects or serious diseases of the fetus is not permitted by Brazilian law. In this related case or similar cases, it would be a serious mistake because this lesion has a good prognosis.

\section{Financial support and sponsorship} Nil.

\section{Conflicts of interest}

There are no conflicts of interest.

\section{REFERENCES}

I. Azam M, O'Donovan DJ. Intracranial cavernous hemangioma and seizures in a newborn infant. J Pediatr 2009; 155:298.

2. Jalloh I, Dean AF, O'Donovan DG, Cross J, Garnett MR, Santarius T. Giant intracranial hemangioma in a neonate. Acta Neurochir (Wien) 20|4;|56:||5|-4.

3. Karmazyn B, Michovitz S, Sirota L, Drozd T, Horev G. Intracranial cavernous hemangioma in a neonate. Pediatr Radiol 200I;3I:6I0-2.

4. Mazza C, Scienza R, Beltramello A, Da Pian R. Cerebral cavernous malformations (cavernomas) in the pediatric age-group. Childs Nerv Syst 1991;7:139-46.

5. Restrepo R, Palani R, Cervantes LF, Duarte AM, Amjad I, Altman NR. Hemangiomas revisited: The useful, the unusual and the new. Part I: Overview and clinical and imaging characteristics. Pediatr Radiol 201।;41:895-904

6. Simon SL, Moonis G, Judkins AR, Scobie J, Burnett MG, Riina HA, et al. Intracranial capillary hemangioma: Case report and review of the literature. Surg Neurol 2005;64:154-9.

7. Winn HR. Youmans Neurological Surgery. $6^{\text {th }}$ ed., Vol. 2. Philadelphia: Elsevier-Saunders; 20I I. p. 2040-2.

8. Yang CY, Hsu JF, Lin KL, Jung SM, Lien R, Chang YL. An extra-axial hemangioma mimicking a large prenatal brain tumor. Brain Dev 2010;32:883-6. 